\title{
Effect of inhaled endotoxin on induced sputum in normal, atopic, and atopic asthmatic subjects
}

Julia A Nightingale, Duncan F Rogers, Lorraine A Hart, Sergei A Kharitonov, K Fan Chung, Peter J Barnes

\begin{abstract}
Background-Inhalation of lipopolysaccharide (LPS) causes an inflammatory response in the lungs. To explore this response, inflammatory indices were measured in induced sputum from atopic asthmatic patients and compared with atopic and non-atopic subjects after inhalation of LPS.
\end{abstract}

Methods-The effects of inhaled LPS $(60 \mu \mathrm{g})$ or placebo $(0.9 \%$ saline $)$ were examined in a randomised, double blind, crossover trial in 11 non-atopic normal subjects, seven atopic, non-asthmatic individuals, and eight atopic, asthmatic patients. Sputum was induced by inhalation of $3.5 \%$ saline before the test inhalation and again at six hours and 24 hours. Spirometry (forced expiratory volume in one second $\left(\mathrm{FEV}_{1}\right)$, forced vital capacity (FVC)), heart rate, blood pressure, and temperature were recorded before challenge and at intervals until eight hours, and at 24 hours after challenge.

Results-There was no change in cardiovascular parameters or spirometry with either exposure in any group. In the asthmatic patients only, inhalation of LPS caused a rise in temperature, with a peak of $0.6^{\circ} \mathrm{C}$ at seven hours, which was significantly higher than following placebo inhalation $(p<0.05)$. In normal subjects, LPS caused a significant rise in absolute neutrophil counts at 24 hours compared with placebo (median $1.1 \times 10^{6}$ cells/ml after LPS; median $0.2 \times 10^{6}$ cells $/ \mathrm{ml}$ after placebo, $p<0.01$ ), but no change in differential counts. In asthmatic patients, LPS caused a significant rise in differential neutrophil counts at six hours compared with placebo (median $88 \%$ after LPS; median $56 \%$ after placebo, $\mathbf{p}<0.05)$, but no change in absolute cell counts at any time point. There was no change in neutrophil counts in the atopic subjects. There was a significant rise in sputum interleukin 8 (IL-8) concentrations in normal subjects at six hours compared with placebo (mean placebo 1.1 $\mathrm{ng} / \mathrm{ml}$; LPS $3.0 \mathrm{ng} / \mathrm{ml}, \mathrm{p}<0.05)$ and in asthmatics at 24 hours (mean placebo 2.0 $\mathrm{ng} / \mathrm{ml}$, LPS $6.9 \mathrm{ng} / \mathrm{ml}, \mathrm{p}<0.05)$. There were no changes in sputum concentrations of tumour necrosis factor $\alpha$ or granulocyte macrophage colony stimulating factor at any time.
Conclusions-Inhalation of LPS causes a neutrophilic inflammation with increases in IL-8 in both normal and asthmatic subjects.

(Thorax 1998;53:563-571)

Keywords: endotoxin; induced sputum; neutrophils; atopy; asthma; interleukin 8

Bacterial lipopolysaccharides (LPS) are constituents of Gram negative bacteria, which are present in the environment, and in the oral and nasal cavities of humans. Exposure to endotoxin occurs in a number of ways; by aspiration of secretions from the mouth and nasopharynx ${ }^{1}$ or by inhalation of endotoxin contaminated water. ${ }^{23}$ Endotoxins are also present in certain types of organic dusts; inhalation of these dusts is thought to be responsible for a number of occupational diseases including byssinosis, ${ }^{4}$ swine worker's disease, ${ }^{5}$ and farmer's lung disease. $^{6}$

Previous exposure studies in man have shown that inhalation of endotoxin leads to impaired lung function ${ }^{7-9}$ and an inflammatory response in the lungs. These studies suggest that asthmatic subjects are more sensitive to the inhalation of LPS than normal subjects in terms of lung function.

The inflammatory response to LPS inhalation consists of increases in various proinflammatory cytokines, such as interleukin 8 (IL-8), IL $1 \beta$, and tumour necrosis factor $\alpha(\mathrm{TNF} \alpha)$, accompanied by neutrophil recruitment ${ }^{10-12}$ in normal subjects ${ }^{10-13}$ and in smokers. ${ }^{11}$ Previous studies of the inflammatory effect of inhaled LPS have examined the early effects on inflammatory cells and cytokines. In this study we used the technique of induced sputum to study the proinflammatory effect of inhaled LPS over a period up to 24 hours in non-atopic, non-asthmatic subjects, in atopic nonasthmatic individuals, and in atopic asthmatics, to determine whether asthma or atopy predispose to a greater inflammatory response to inhaled LPS in the lungs.

\section{Methods}

SUBJECTS

Eleven healthy non-atopic, non-asthmatic volunteers were studied; mean age 25.5 years. All had normal bronchial reactivity (provocative concentration $(\mathrm{PC})_{20}$ methacholine $>64 \mathrm{mg} /$ $\mathrm{ml}$ ) and were non-atopic on skin prick testing to common aeroallergens (cat, Aspergillus fumigatus, grass pollen and Dermatophagoides pteronyssinus). They reported no history of respiratory or allergic disease and were on no 
Table 1 Characteristics of asthmatic patients

\begin{tabular}{lllll}
\hline Patient & Age (years) & $F E V_{1}(\%$ predicted $)$ & $P C_{20}(\mathrm{mg} / \mathrm{ml})$ & Atopy \\
\hline 1 & 21 & 74.8 & 0.114 & C, GP, HD \\
2 & 35 & 95.8 & 8.0 & C, GP, HD \\
3 & 18 & 77.5 & 0.58 & GP, HD \\
4 & 25 & 108.8 & 0.43 & HD, GP, C \\
5 & 24 & 113.1 & 4.49 & GP, HD \\
6 & 22 & 99.8 & 0.29 & GP \\
7 & 29 & 93 & 3.6 & C, HD, GP \\
8 & 35 & 80.9 & 4.5 & C, HD \\
Mean (SEM) & $26.1(2.2)$ & $93.0(5.1)$ & $2.75(1.0)$ & \\
\hline
\end{tabular}

$\mathrm{PC}_{20}$, dose of methacholine required to cause a $20 \%$ drop in $\mathrm{FEV}_{1}$.

$\mathrm{HD}$, house dust mite; GP, grass pollen; C, cat.

medications. We also studied seven atopic, non-asthmatic subjects (mean age 23.9 years), who had normal bronchial reactivity, but a positive skin prick test to at least one allergen and a history of symptoms on relevant allergen exposure. None was taking medication at the time of the trial. We also studied eight mild asthmatic volunteers (as defined by American Thoracic Society criteria $\left.^{14}\right)$, mean age 26.0 years, with a forced expiratory volume in one second $\left(\mathrm{FEV}_{1}\right)>70 \%$ predicted, and all were atopic. All had a $\mathrm{PC}_{20}$ methacholine $<8 \mathrm{mg} / \mathrm{ml}$, and were controlled with $\beta_{2}$ agonists only. None was taking inhaled or oral steroids at the time of the study or for eight weeks before the trial (table 1). All subjects were male, and nonsmokers or ex-smokers for more than five years. None had suffered from an upper respiratory tract infection in the previous eight weeks. Written informed consent was obtained from all volunteers. The study was approved by the ethics committee of the Royal Brompton Hospital and the National Heart \& Lung Institute.

MATERIALS

The LPS solution was prepared by dissolving 4 mg Escherichia coli endotoxin (Sigma Chemicals, Poole, Dorset, UK) in $3 \mathrm{ml}$ endotoxin free sterile $0.9 \%$ saline before use. Saline solution was used as a placebo. Both solutions were delivered with a breath activated nebuliser (Mefar Dosimeter MB3, Brescia, Italy). The nebuliser delivered particles with an aerodynamic mass median diameter of 3.4 to $4 \mu \mathrm{m}$. Subjects inhaled five breaths of each solution (60 $\mu \mathrm{g}$ LPS or placebo).

LUNG FUNCTION MEASUREMENTS

$\mathrm{FEV}_{1}$ and forced vital capacity (FVC) were measured using a dry wedge spirometer (Vitalograph, Buckingham, Buckinghamshire, UK). Values were expressed as per cent predicted normal. Baseline values were measured after 15 minutes' rest and taken as the highest of three readings. Single readings only were taken at other times. The level of bronchial reactivity was assessed by methacholine challenge performed according to a standardised technique. ${ }^{15}$ The dose required to cause a $20 \%$ drop in $\mathrm{FEV}_{1}\left(\mathrm{PC}_{20}\right)$ was determined by linear interpolation of the concentration- $\mathrm{FEV}_{1}$ response curve.

SPUTUM INDUCTION PROCEDURE

Subjects inhaled $3.5 \%$ saline for 15 minutes in total, via an ultrasonic nebuliser (DeVilbiss
2000, DeVilbiss Co, Heston, Middlesex, UK) with a calibrated mass median aerodynamic diameter of $4.5 \mu \mathrm{m}$, and output of $4.5 \mathrm{ml} / \mathrm{min}$. The aerosol was inhaled through a tube $110 \mathrm{~cm}$ long with an internal diameter of $22 \mathrm{~mm}$ equipped with a mouthpiece, with the subject's nose clipped. Subjects discarded saliva into a bowl and mouth washed before each expectoration. Any secretions collected during the first five minutes were discarded to minimise squamous epithelial cell contamination. Subjects were encouraged to cough deeply at five minute intervals and any other time they felt the need. Secretions expectorated over the final 10 minutes were kept at $4^{\circ} \mathrm{C}$ for not more than two hours before processing. For safety reasons, all asthmatic subjects were premedicated with $200 \mu \mathrm{g}$ inhaled salbutamol before the sputum induction procedure to prevent bronchoconstriction from the hypertonic saline.

\section{SPUTUM PROCESSING}

The whole sputum sample was processed as described previously. ${ }^{16}$ Sputum was diluted with Hank's balanced salt solution (HBSS) containing 1\% dithiothreitol (DTT) (Sigma Chemicals) and vortexed at room temperature. When homogeneous, the volume was recorded and the sample was diluted further with HBSS and centrifuged at $300 \mathrm{~g}$ for 10 minutes. The supernatant was separated and frozen at $-70^{\circ} \mathrm{C}$ until further analysis. The cell pellet was resuspended in HBSS. Total cell counts were determined on a haemocytometer slide using Kimura stain and slides were prepared using a cytospin (Shandon, Runcorn, Cheshire, UK) and stained with May-GrunwaldGiemsa stain. Differential cell counts were performed by a "blinded" observer. Three hundred non-squamous cells were counted on two slides for each sample. Differential cell counts are expressed as a percentage of lower airway cells - that is, excluding squamous epithelial cells.

\section{TNF $\alpha$ ASSAY}

$\mathrm{TNF} \alpha$ concentrations were measured using an amplified sandwich enzyme linked immunosorbent assay (ELISA). Ninety six well microtitre plates (Greiner Labortecnik Ltd, Dursley, Gloucestershire, UK) were coated with $100 \mu \mathrm{l}$ mouse monoclonal antiTNF $\alpha$ antibody (NBS Biologicals, Huntingdon, Cambridgeshire, UK) at a 1:400 dilution and incubated for two hours at $37^{\circ} \mathrm{C}$. Plates were then washed with phosphate buffered saline (PBS) containing $0.05 \% \mathrm{vol} / \mathrm{vol}$ Tween 20 and blocked with bovine serum albumin (BSA) 5\% wt/vol for 25 minutes at $37^{\circ} \mathrm{C}$. The plates were washed again and $\mathrm{TNF} \alpha$ standards (containing $0.2 \% \mathrm{DTT}$ ) and sputum supernatant samples were added in duplicate and incubated at $4^{\circ} \mathrm{C}$ for 18 hours. Plates were washed and incubated at room temperature for two hours with $100 \mu \mathrm{l}$ rabbit antihuman $\mathrm{TNF} \alpha$ polyclonal antibody (Genzyme Diagnostics, West Malling, UK). After a further wash, an alkaline phosphatase conjugated donkey antirabbit polyclonal IgG antibody (Jaxon/Stratech Scientific Ltd, Luton, Bedfordshire, UK) diluted 1:2000 was added 


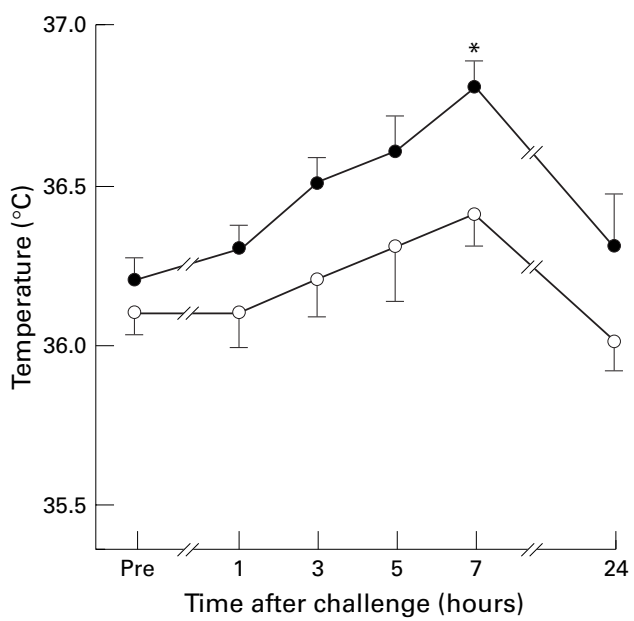

Figure 1 Change in temperature following inhalation of LPS (closed circles) or placebo (open circles) in asthmatic patients. Values shown as mean (SE). ${ }^{\star} p<0.05$ compared with placebo at seven hours after challenge.

and incubated for two hours at room temperature. Excess antibody was washed off and plates were developed with a $p$-nitro-phenyl phosphate assay kit (number 50-80-00; KPL/ Dynatech Laboratories Ltd, Billinghurst, Sussex, UK). The optical density of the wells was read at $405 \mathrm{~nm}$ using a plate photometer and quantified by interpolation on a standard curve of known concentrations of human recombinant TNF in the range 8 to $800 \mathrm{pg} / \mathrm{ml}$ (RD Systems, Abingdon, Oxfordshire, UK). The lower detection limit of the assay is $8 \mathrm{pg} / \mathrm{ml}$.

IL-8 ASSAY

IL-8 concentrations were measured using an amplified sandwich ELISA. Ninety six well microtitre plates were coated with $100 \mu \mathrm{l}$ mouse monoclonal antihuman IL-8 antibody (Genzyme Diagnostics) at a concentration of $2.5 \mu \mathrm{g} / \mathrm{ml}$ and incubated overnight at $4^{\circ} \mathrm{C}$. Plates were washed with PBS containing $0.05 \% \mathrm{vol} / \mathrm{vol}$ Tween 20 and immediately blocked with BSA $1 \% \mathrm{wt} / \mathrm{vol}$ for two hours at $37^{\circ} \mathrm{C}$. Plates were decanted and IL -8 standards (containing $0.2 \%$ DTT) and sputum supernatant samples were added in duplicate and incubated at $37^{\circ} \mathrm{C}$ for one hour. Plates were washed and incubated at $37^{\circ} \mathrm{C}$ for one hour with $100 \mu \mathrm{l}$ rabbit antihuman IL-8 polyclonal antibody (Genzyme Diagnostics). After a further wash, streptavidin horseradish peroxidase (Genzyme Diagnostics) diluted in $0.05 \%$ PBS Tween 20 with $1 \%$ BSA was added and incubated for 15 minutes at $37^{\circ} \mathrm{C}$. Following a further wash, $100 \mu \mathrm{l}$ tetramethylbenzidine (TMB) (Sigma Chemicals) was added and plates were left for 20 minutes at room temperature. The colour reaction was stopped with $2 \mathrm{~N}$ sulphuric acid (Sigma Chemicals). Optical density of the wells was read at $450 \mathrm{~nm}$ using a plate photometer and quantified by interpolation from a standard curve constructed to known concentrations (16 to 2000 $\mathrm{pg} / \mathrm{ml}$ ) of human recombinant IL-8 (Genzyme Diagnostics).
GM-CSF ASSAY

Rat antihuman granulocyte macrophage colony stimulating factor (GM-CSF) monoclonal antibody (Pharmingen, San Diego, California, USA) was diluted to $2 \mu \mathrm{g} / \mathrm{ml}$ in $\mathrm{NaHCO}_{3}(\mathrm{pH} 8.2)$, and $50 \mu \mathrm{l}$ added to each well of a 96 well plate and incubated at $4^{\circ} \mathrm{C}$ for 16 hours. Wells were washed with PBS/Tween $200.05 \% \mathrm{wt} / \mathrm{vol} ; 200 \mu \mathrm{lPBS} / 10 \%$ fetal calf serum was added to the wells and incubated at room temperature for two hours. Plates were washed again with PBS/Tween. Then $100 \mu \mathrm{l}$ of standards ( 16 to $2000 \mathrm{pg} / \mathrm{ml}$ ) made up in $0.2 \%$ DTT and $100 \mu \mathrm{l}$ of samples were added in duplicate to the plates. Plates were then incubated for 16 hours at $4^{\circ} \mathrm{C}$. Next, $100 \mu \mathrm{l}$ biotinylated rat antihuman GM-CSF monoclonal antibody (Pharmingen) was added and incubated for 45 minutes at room temperature before washing six times. Then $100 \mu$ of a $1: 400$ dilution of $1 \mathrm{mg} / \mathrm{ml}$ stock avidin peroxidase (Sigma Chemicals) was added and incubated at room temperature for 30 minutes before further washing. Finally, $10 \mu \mathrm{l}$ hydrogen peroxide was added to ABTS (2,2'-azino-bis (3-ethylbenz-thiazoline-6-sulphonic acid)) substrate (Sigma Chemicals) and $100 \mu \mathrm{l}$ added to each well. Colour was developed for 60 minutes and optical density read at $405 \mathrm{~nm}$ using a plate photometer. A standard curve was constructed and sample values were determined by interpolation.

\section{STUDY DESIGN}

The trial was double blind, randomised, placebo controlled, and crossover. An initial screening visit involved a full medical history, physical examination, spirometry $\left(\mathrm{FEV}_{1}\right.$ and FVC), skin prick testing, and a methacholine challenge. Subjects were then classified as normal, atopic, or asthmatic on the basis of these results.

Subjects reattended on a separate study day at $8 \mathrm{am}$ and underwent a number of baseline investigations of spirometry, oral temperature, pulse, and blood pressure measurement. A baseline sample of sputum was collected by inhalation of hypertonic saline. Subjects were then randomised to inhale either $60 \mu \mathrm{g}$ LPS or saline placebo. Subjects remained under observation and spirometry was repeated hourly for eight hours. Temperature, pulse, and blood pressure were measured every two hours. A repeat sputum sample was collected six hours after the challenge. Subjects were then allowed home and reattended 24 hours after the original challenge, at which time all the above procedures were repeated and subjects were questioned about any symptoms. After a four week washout, subjects reattended and the whole process was repeated with the opposite challenge solution.

\section{ANALYSIS OF DATA}

Cardiovascular parameters, temperature, and spirometry were analysed using repeated measures analysis of variance (ANOVA). Where differences were found the peak value following exposure was taken as a summary measurement. Comparisons between placebo 
and LPS exposure were then made using a paired $t$ test. Results of supernatant assays were compared using a paired $t$ test to examine differences between exposures at six hours and 24 hours within each group of subjects. Comparisons between groups were initially made using ANOVA, followed by a non-paired $t$ test where the ANOVA was significant. Results of parametric data are expressed as means with $95 \%$ confidence intervals (CI), unless stated otherwise. Cell count data are not normally distributed and are expressed as medians throughout. The Wilcoxon signed rank test was used to compare cell counts following placebo and LPS exposure at six and 24 hours within each subject group. Differences between groups were analysed using the Kruskal Wallis test. If this was significant, pairwise comparisons were
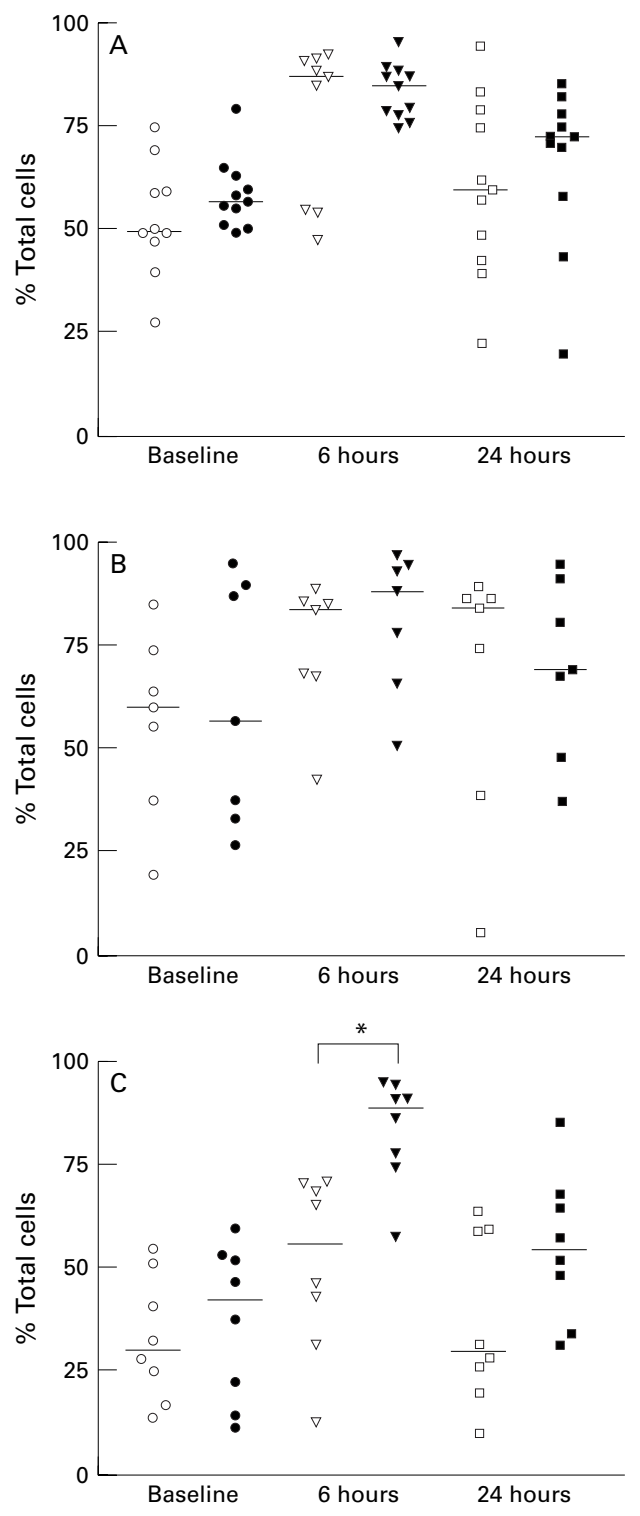

Time of sputum induction made using the Mann-Whitney rank sum test. Correlations were calculated using Spearman's rank correlation coefficient. For all tests, $\mathrm{p}<0.05$ was considered significant.

\section{Results}

ADVERSE EVENTS

Two of the normal subjects reported having a mild headache in the evening following the inhalation of LPS. Neither subject required any treatment and the headache resolved within 24 hours in both cases.

\section{CARDIOVASCULAR PARAMETERS}

There was no significant change in pulse rate or blood pressure at any time point following challenge with inhaled LPS or placebo.
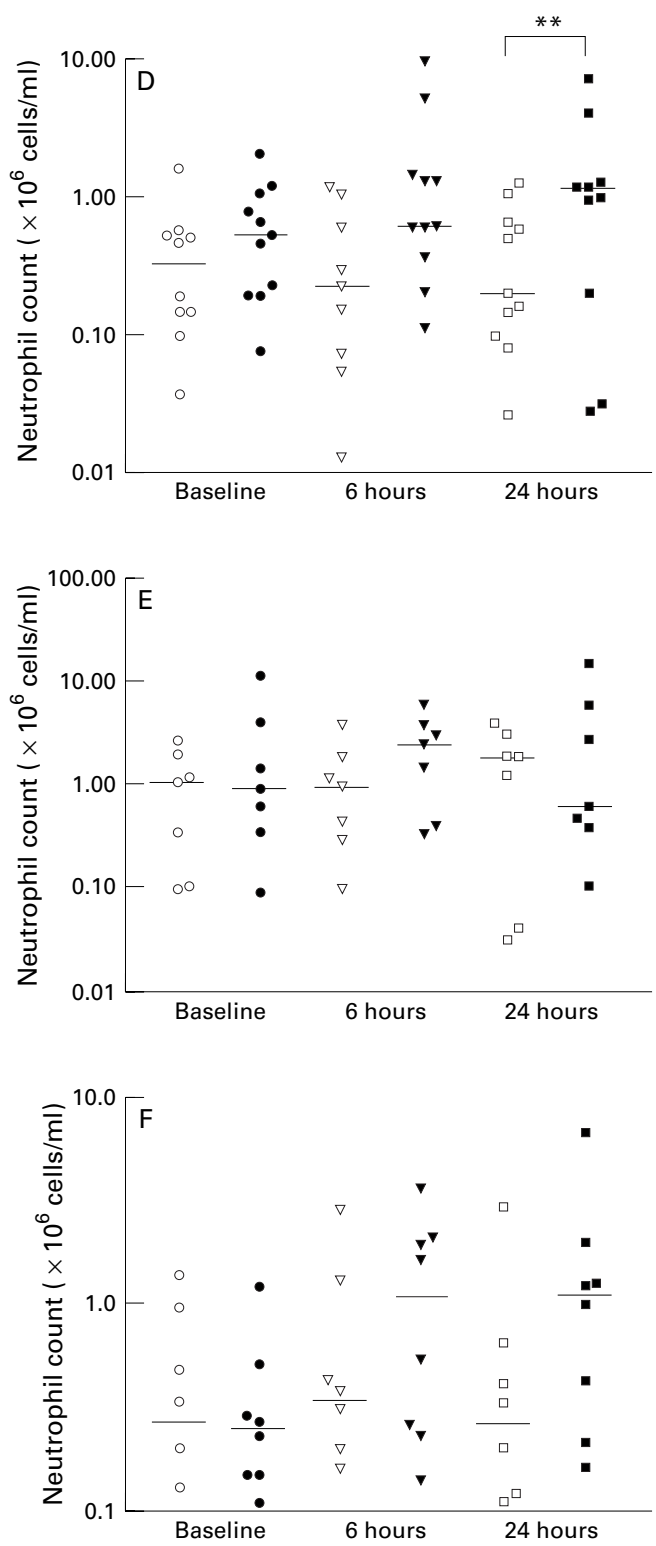

Time of sputum induction

Figure 2 Effect of LPS inhalation on sputum neutrophils. Differential and absolute neutrophil counts following LPS (closed symbols) and placebo exposure (open symbols). Differential counts in normal subjects (A), atopic subjects (B), and asthmatic patients (C). Absolute neutrophil counts in normal subjects (D), atopic subjects (E), and asthmatic patients (F). Values are shown as individual data points with medians. Absolute counts are given on a logarithmic scale. ${ }^{\star} p<0.05$, ${ }^{\star *} p<0.01$ compared with placebo. 
TEMPERATURE

There was no significant change in oral temperature at any time in normal or atopic subjects. In the asthmatic group, inhalation of LPS caused an increase in temperature, with a peak rise of $0.6^{\circ} \mathrm{C}$ at seven hours, which was significantly higher than following placebo inhalation $(\mathrm{p}<0.05$, fig 1$)$.

SPIROMETRY

There was no difference in the baseline FEV, between the three groups (normals $103.5 \%$ of predicted value, $95 \%$ CI 92.7 to 114.3 ; atopics $100.1 \%, 95 \%$ CI 86.4 to 113.9 ; and asthmatics $93.0 \%, 95 \%$ CI 81.0 to 104.9$)$. There was no significant change in either $\mathrm{FEV}_{1}$ or FVC following LPS or placebo in any of the groups.
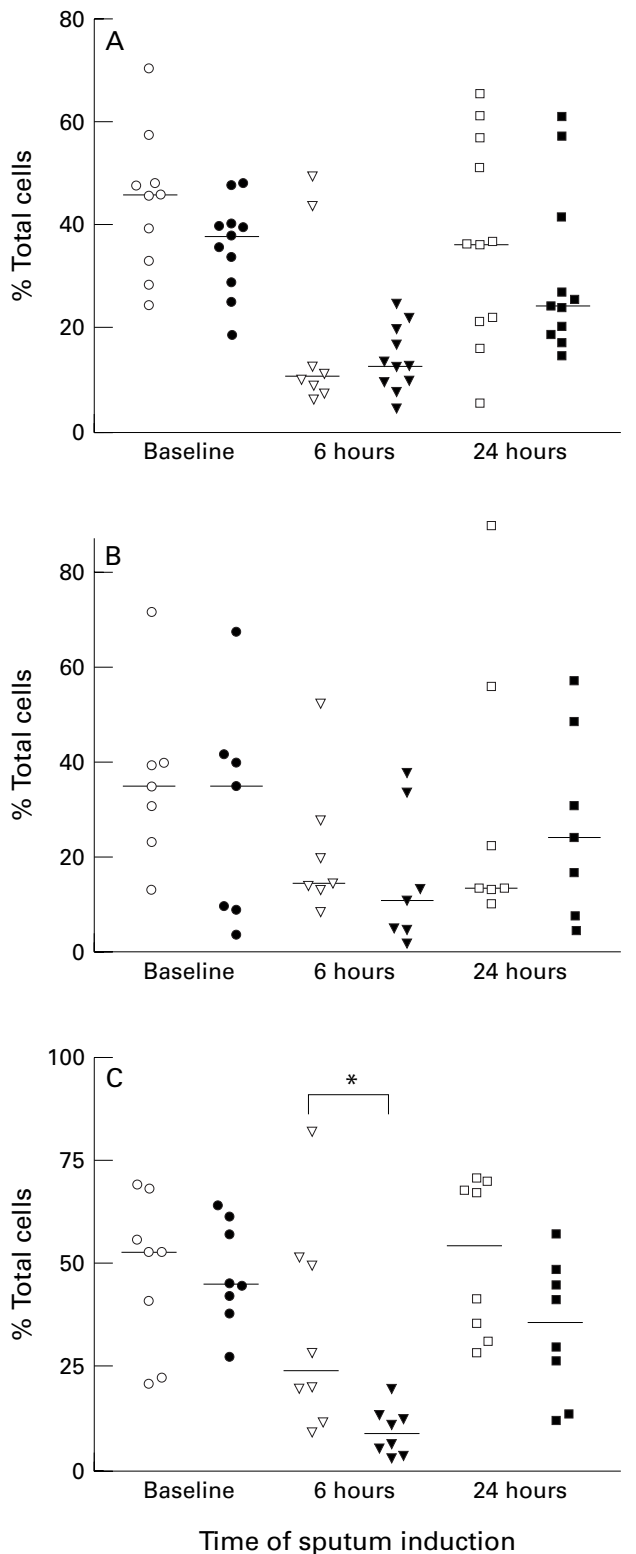

SPUTUM CELL COUNTS

All but three sputum samples were adequate for analysis and data for these (one normal baseline and two normal subjects at six hours after placebo) were excluded from the analysis.

In normal subjects, there was a significant approximate fivefold increase in the absolute neutrophil count following LPS inhalation compared with placebo at 24 hours $(\mathrm{p}<0.01$, fig 2D). There was an increase of 25 to $32 \%$ in differential neutrophil counts at six hours after inhalation of either LPS or placebo (fig 2A), but no significant difference between exposures at this time point. There was no significant difference between placebo or LPS exposure in the differential or absolute counts of
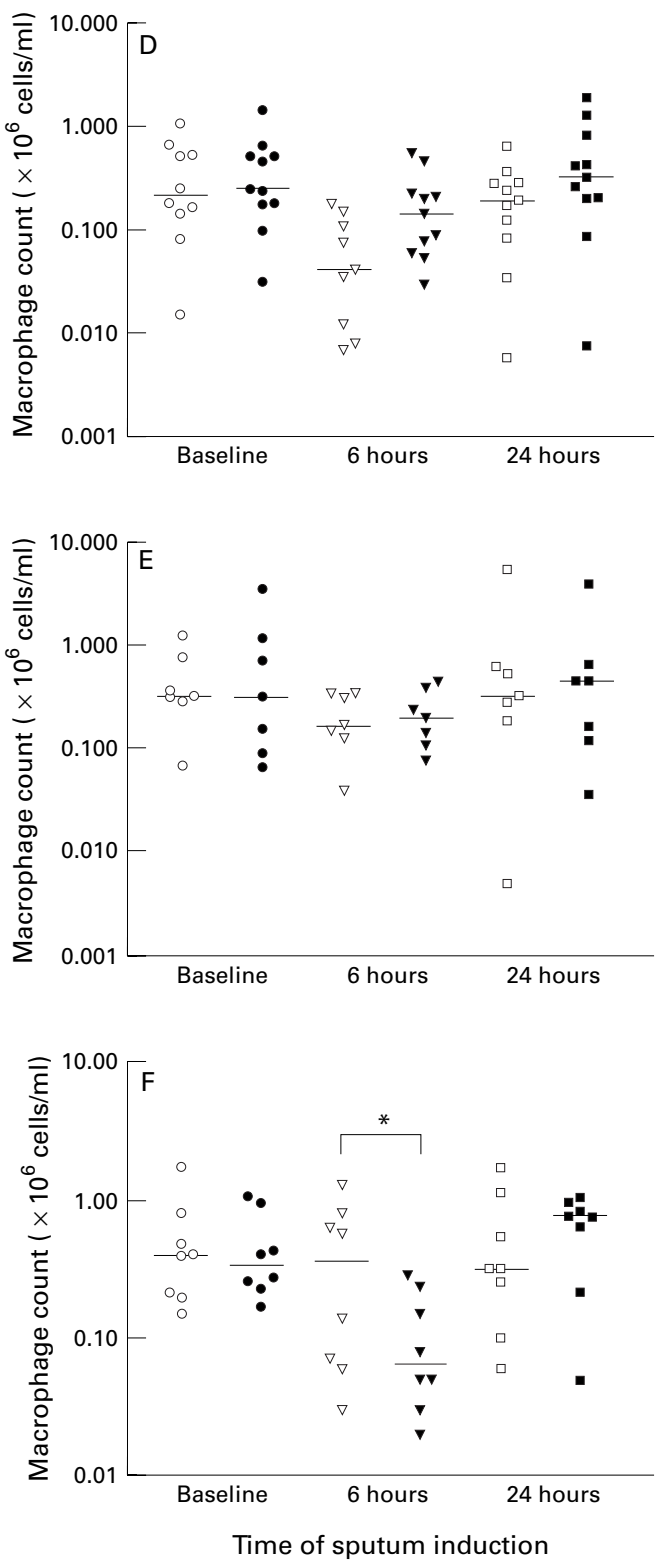

Figure 3 Effect of LPS inhalation on sputum macrophages. Differential and absolute macrophage counts following LPS (closed symbols) and placebo exposure (open symbols). Differential counts in normal subjects $(A)$, atopic subjects (B) and asthmatic patients (C). Absolute macrophage counts in normal subjects (D), atopic subjects (E) and asthmatic patients (F). Values are shown as individual data points with medians. Absolute counts are given on a logarithmic scale. ${ }^{\star} p<0.05$ compared with placebo. 
macrophages (fig 3A and 3D), eosinophils, lymphocytes or epithelial cells at any time point.

In atopic subjects, there was a similar increase in differential neutrophils at six hours (fig 2B) following placebo or LPS, but no difference between the two exposures. There were no changes in absolute neutrophil counts in this group (fig 2E). There were no significant differences between placebo and LPS exposures in differential or absolute counts of macrophages (fig $3 \mathrm{~B}$ and $3 \mathrm{E}$ ), eosinophils, lymphocytes, or epithelial cells at any time point.

In asthmatic patients, inhalation of LPS caused a significant rise in neutrophils of $32 \%$ above placebo at six hours $(\mathrm{p}<0.05)$, and this remained raised at 24 hours, albeit not significantly (fig 2C). There were no significant differences in the absolute neutrophil counts following LPS inhalation compared with placebo (fig $2 \mathrm{~F}$ ). Both the differential and absolute macrophage counts at six hours were significantly lower in the LPS treated group compared with placebo $(\mathrm{p}<0.05$, fig $3 \mathrm{C}$ and $3 \mathrm{~F})$. There were no significant differences in the differential or
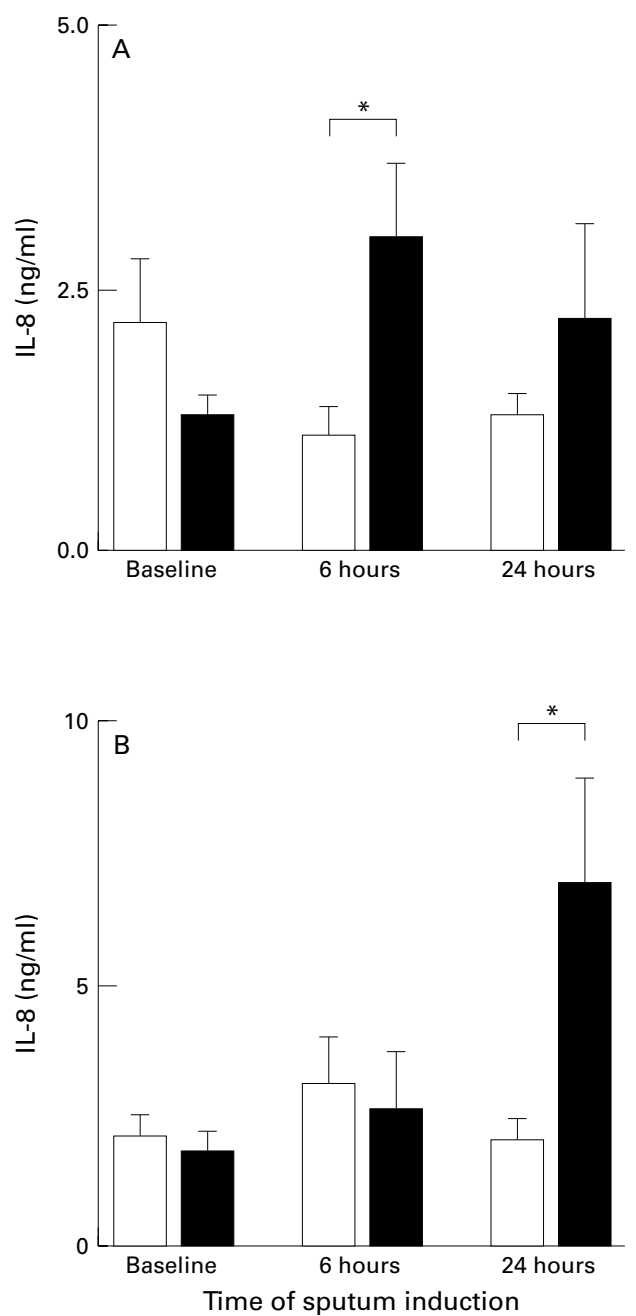

Figure 4 Effect of LPS inhalation on sputum supernatant IL-8 concentrations. IL-8 concentrations following LPS (closed bars) and placebo exposure (open bars) in normal subjects (A) and asthmatic patients (B). Values are mean (SE). ${ }^{*} p<0.05$ compared with placebo. Correlation between $I L-8$ concentrations and absolute neutrophil counts in normal subjects $(C)$ and asthmatics (D).

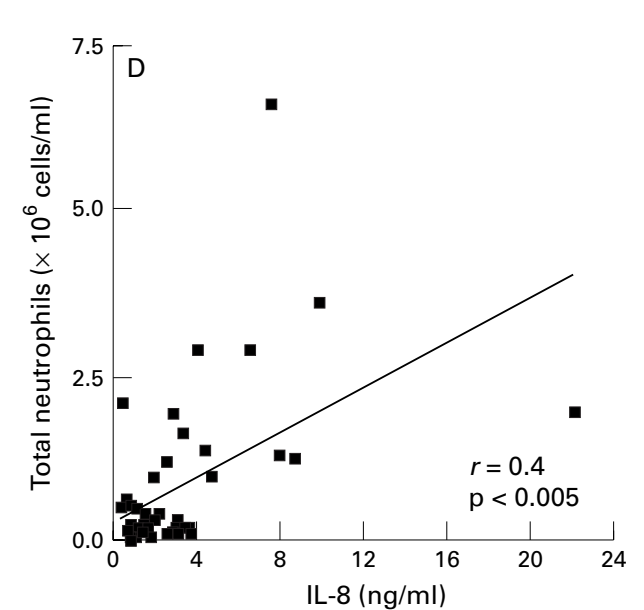

absolute counts of eosinophils, lymphocytes, or epithelial cells between placebo or LPS exposures.

A comparison of the difference in differential neutrophil counts between placebo and LPS exposure within each subject group demonstrated a significantly greater difference at six hours in asthmatic subjects compared with normal subjects (mean increase in normal subjects $7.1 \%, 95 \%$ CI -9.4 to 23.7 ; mean increase in asthmatics $32.1 \%, 95 \%$ CI 13.9 to 50.4; $\mathrm{p}<0.05$; compare fig $2 \mathrm{~A}$ and $2 \mathrm{C}$ ). No difference was found between groups for absolute neutrophil counts. A comparison of the difference in absolute macrophage counts between placebo and LPS exposure within each subject group demonstrated a significantly greater difference at six hours in asthmatic subjects compared with normal subjects (mean decrease in asthmatic patients of 34.2 million cells $/ \mathrm{ml}, 95 \%$ CI 0.6 to 67.9 ; mean increase in normal subjects of 13.6 million cells $/ \mathrm{ml}, 95 \% \mathrm{CI}-0.3$ to $27.5, \mathrm{p}<0.05$; compare fig $3 \mathrm{D}$ and $3 \mathrm{~F}$ ). No difference was found between groups for the differential macrophage counts.

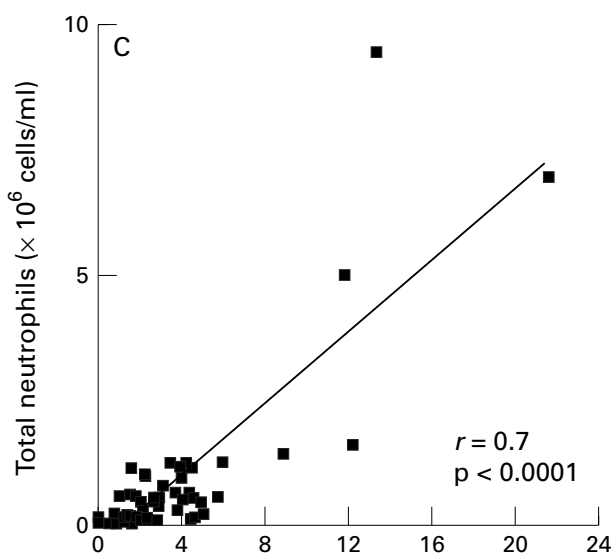


Table 2 Mean (SE) GM-CSF $(\mathrm{ng} / \mathrm{ml})$ and TNFa $(\mathrm{pg} / \mathrm{ml})$ concentrations in normal and asthmatic subjects following inhalation of endotoxin or placebo

\begin{tabular}{|c|c|c|c|c|c|c|}
\hline & \multicolumn{3}{|l|}{ Placebo } & \multicolumn{3}{|l|}{ Endotoxin } \\
\hline & Baseline & 6 hours & 24 hours & Baseline & 6 hours & 24 hours \\
\hline \multicolumn{7}{|l|}{ Normal } \\
\hline GM-CSF & $0.5(0.1)$ & $0.5(0.1)$ & $0.6(0.1)$ & $0.5(0.1)$ & $0.5(0.1)$ & $0.5(0.1)$ \\
\hline $\mathrm{TNF} \alpha$ & $0.0(0.0)$ & $49.0(23.0)$ & $18.6(9.7)$ & $25.1(16.6)$ & $56.7(48.0)$ & $27.1(20.4)$ \\
\hline \multicolumn{7}{|l|}{ Asthma } \\
\hline GM-CSF & $0.6(0.1)$ & $0.6(0.1)$ & $0.4(0.05)$ & $0.5(0.1)$ & $0.4(0.1)$ & $0.6(0.1)$ \\
\hline $\mathrm{TNF} \alpha$ & $84.9(38.7)$ & $127.0(76.6)$ & $81.6(36.6)$ & $112.0(42.9)$ & $41.4(28.2)$ & 45.5 (21.6) \\
\hline
\end{tabular}

SUPERNATANT ASSAYS

Data for a number of the supernatant samples were unavailable due to degradation during storage. Data were available for all samples in the asthmatic patient group. Complete data were available for six of the normal subjects, and a total of nine data points were missing from the remaining five patients. In view of the small number available for the atopic subjects we did not perform any statistical analysis in this group.

There was no difference in the baseline concentrations of IL- 8 between normal subjects (1.7 ng/ml, 95\% CI 1.0 to 2.4 ) and asthmatics $(2.0 \mathrm{ng} / \mathrm{ml}, 95 \% \mathrm{CI} 1.4$ to 2.5$)$. In the normal subjects there was an increase in IL-8 at six hours after LPS (3.0 ng/ml, 95\% CI 1.3 to 4.7 ) that was significantly higher than after placebo ( $1.0 \mathrm{ng} / \mathrm{ml}, 95 \%$ CI 0.4 to $1.7, \mathrm{p}<0.05$, fig $4 \mathrm{~A}$ ). In the asthmatic group there was a rise in IL-8 at 24 hours $(6.9 \mathrm{ng} / \mathrm{ml}, 95 \%$ CI 2.1 to 11.7$)$ that was significantly higher than the placebo group $(2.0 \mathrm{ng} / \mathrm{ml}, 95 \%$ CI 1.0 to $3.1, \mathrm{p}<0.05$, fig $4 \mathrm{~B})$. There was a significant positive correlation between IL-8 concentrations and absolute neutrophil counts in normal subjects $(r=$ $0.7, \mathrm{p}<0.0001$, fig 4C) and a weaker correlation in asthmatics ( $r=0.4, \mathrm{p}<0.005$, fig 4D). A comparison of the difference in IL-8 concentrations between placebo and LPS exposure within each subject group demonstrated a significantly greater difference at six hours in normal subjects compared with asthmatic subjects (mean increase in normal subjects $2.0 \mathrm{ng} / \mathrm{ml}$, $95 \%$ CI 0.7 to 3.4 ; mean decrease in asthmatics $0.5 \mathrm{ng} / \mathrm{ml}, 95 \% \mathrm{CI}-2.6$ to $1.5 ; \mathrm{p}<0.05$; compare fig $4 \mathrm{~A}$ and $4 \mathrm{~B}$ ). There was no significant difference between the groups at 24 hours.

Mean baseline concentrations of $\mathrm{TNF} \alpha$ for both exposures combined were significantly higher in asthmatics (98.4 pg/ml, 95\% CI 38.4 to 158.4 ) than in normal subjects $(13.5 \mathrm{pg} / \mathrm{ml}$, $95 \%$ CI 0 to $33.9, \mathrm{p}<0.05)$. There was no significant change in the $\mathrm{TNF} \alpha$ concentrations in the asthmatic or the normal subjects at any time point following LPS (table 2).

There was no difference between mean baseline concentrations of GM-CSF, for both exposures combined, in normal and asthmatic subjects (normals $0.5 \mathrm{ng} / \mathrm{ml}, 95 \%$ CI 0.3 to 0.7 ; asthmatics $0.6 \mathrm{ng} / \mathrm{ml}, 95 \%$ CI 0.4 to 0.7 ). The concentrations of GM-CSF did not change following LPS in either group (table 2).

\section{Discussion}

The present study demonstrated that inhalation of $60 \mu \mathrm{g}$ LPS causes an increase in neutrophils in induced sputum in normal and asthmatic patients but not in atopic subjects. We also showed increases in sputum IL-8 at six hours in normal subjects and at 24 hours in asthmatic patients.

The dose of $60 \mu \mathrm{g}$ endotoxin chosen in our experiment was calculated to equate with the amount of endotoxin that workers are likely to be exposed to in an occupational setting. For example, cotton mill workers are exposed to airborne concentrations of 0.15 to 0.46 $\mu \mathrm{g} / \mathrm{m}^{3} .{ }^{17}$ Other occupations lead to exposures of up to $1 \mu \mathrm{g} / \mathrm{m}^{3} .{ }^{18}$ However, these values were measured by the Limulus lysate assay, which is inaccurate in the measurement of endotoxin bound to cells. This assay tends to underestimate the actual value of endotoxin by approximately 10-fold compared with chemical assays, ${ }^{8}$ giving occupational exposure concentrations of 1.5 to $10 \mu \mathrm{g} / \mathrm{m}^{3}$. Assuming a respiratory volume of $1.5 \mathrm{~m}^{3} / \mathrm{h}$ and an eight hour shift in an environment with an endotoxin concentration of $5 \mu \mathrm{g} / \mathrm{m}^{3}$, subjects would be exposed to an actual dose of endotoxin of approximately $60 \mu \mathrm{g}$.

Inhalation of LPS has previously been shown to affect lung function in both normal subjects and asthmatics. In normal subjects the effect of inhalation of LPS on FEV 1 appears to be dose related. Doses of LPS up to $100 \mu \mathrm{g}$ have no effect on $\mathrm{FEV}_{1}$ in normal subjects, ${ }^{8} 91920$ whereas a dose of $200 \mu \mathrm{g}$ causes a significant fall in $\mathrm{FEV}_{1}{ }^{8}$ This is consistent with the present study, which found no effect on $\mathrm{FEV}_{1}$ in normal subjects after $60 \mu \mathrm{g}$ LPS.

Asthmatic subjects appear to be more sensitive to the effects of inhaled LPS, with doses as low as $20 \mu \mathrm{g}$ causing small but significant falls in $\mathrm{FEV}_{1}$ of 5 to $8 \%$ from baseline. ${ }^{92122}$ In contrast, we did not demonstrate a significant fall in $\mathrm{FEV}_{1}$ in the asthmatic subjects in the present study. This finding is not unexpected as the asthmatic subjects were premedicated with 200 $\mu \mathrm{g}$ inhaled salbutamol before the induction of sputum, approximately 30 minutes before the challenge exposure. This pretreatment with inhaled salbutamol is standard practice in our laboratory for safety reasons to prevent the bronchoconstriction that can occur in asthmatic subjects following the inhalation of hypertonic saline. ${ }^{23}$ The asthmatic subjects did, however, have a small but significant rise in temperature following LPS, which was significantly higher than the value following the placebo exposure.

Previous studies have demonstrated a proinflammatory effect of endotoxin inhalation in both animal and human exposure studies. Previous human exposure studies have shown 
increases in peripheral blood neutrophils following inhalation of endotoxin in normal subjects $^{24}$ and asthmatics. ${ }^{21}$ Bronchoscopy studies in healthy subjects have also shown increases in bronchoalveolar lavage (BAL) neutrophils at three hours ${ }^{10}$ and at 90 and 240 minutes in healthy non-smoking volunteers and healthy smokers. ${ }^{11} \mathrm{~A}$ recent study in normal volunteers ${ }^{12}$ showed increases in induced sputum neutrophils with a dose as low as $5 \mu \mathrm{g}$ LPS. Our study demonstrated a rise in absolute neutrophil counts in induced sputum from normal subjects following LPS inhalation compared with placebo at 24 hours. There was also a rise in neutrophil percentage following LPS in the normal subjects at six hours but no significant difference between the placebo and LPS groups at this time point, as there was also a notable rise after the placebo inhalation. The most likely explanation for this rise in neutrophils after placebo inhalation is a proinflammatory effect of the hypertonic saline used for the sputum induction. We have previously shown that repeated sputum induction alone causes a significant rise in percentage neutrophils in normal subjects at eight hours. ${ }^{25}$ This effect may also be responsible for the neutrophil increase seen in the atopic subjects after placebo in the present study. We have not demonstrated a rise in either differential or absolute neutrophil counts in the atopic group, suggesting that atopy does not increase the inflammatory effect of inhaled LPS. In the asthmatic patients there is a definite increase in percentage neutrophils at six hours with a non-significant increase in absolute neutrophil counts at six and 24 hours. A comparison of the difference in differential neutrophil counts between placebo and LPS exposure within each subject group demonstrated a significantly greater difference at six hours in asthmatic subjects compared with normal subjects. However, this difference may not be clinically significant as the absolute values of the differential counts are similar for the two groups at six hours (median in normals $84.2 \%$, median in asthmatics $88.2 \%)$.

We also found a greater decrease in both differential counts and absolute numbers of macrophages in the asthmatic subjects at six hours after LPS inhalation compared with the placebo exposure, but no significant change in the atopic or normal subjects. For the normal subjects, our data are consistent with previous observations of no significant change in macrophage number in BAL fluid after inhalation of LPS, ${ }^{10}{ }^{11}$ although a recent study showed a trend for reduction of macrophage numbers in induced sputum after LPS. ${ }^{12}$ To our knowledge, there are no previous studies demonstrating changes in macrophage number in BAL fluid or sputum of asthmatics after inhalation of LPS, although a decrease in macrophage counts in BAL fluid has been demonstrated in guinea pigs following inhalation of LPS. $^{26}$ The mechanism underlying the reduction in macrophages in the present study is not known. A possible explanation is that LPS limits macrophage influx into the airway lumen, with a concomitant reduction in number in the sputum. It has been shown that LPS stimulation of human BAL macrophages in vitro changes the expression of very late antigen (VLA) 2, 3, and 5 and of fibronectin, which may be consistent with impairment of VLA mediated migration, resulting in local accumulation of macrophages in the lung. ${ }^{27}$ This suggestion is supported by a study demonstrating increased adhesion of rat BAL macrophages to a type II pulmonary epithelial cell line following in vivo tracheal instillation of LPS. ${ }^{28}$ An alternative explanation is that the inhalation of endotoxin causes an increase in apoptosis of macrophages, an effect that has been demonstrated in human alveolar macrophages exposed in vitro to LPS. ${ }^{29}$

We have shown a significant increase in the concentrations of IL-8 after LPS in normal subjects at six hours compared with placebo. We also demonstrated a rise in sputum IL-8 concentrations in asthmatic subjects following LPS inhalation. In the asthmatic subjects, however, this rise did not occur until 24 hours. IL-8 has been implicated as underlying the attraction of neutrophils after LPS inhalation. ${ }^{11}$ Previous studies have demonstrated an early rise in BAL concentrations of $\mathrm{IL}-8$ following LPS inhalation in both smokers and non-smokers. ${ }^{11}$ This is consistent with our data for normal subjects. However, the rise in neutrophils in the asthmatic group precedes the rise in IL-8 concentrations, suggesting other neutrophil chemoattractants may be involved in asthmatic subjects. Further support for this conclusion comes from the finding that there is a significant correlation between absolute neutrophil counts and IL-8 concentrations in the normal subjects in our study $(r=$ $0.7, \mathrm{p}<0.001)$, while the correlation between neutrophils and IL-8 concentrations in the asthmatic group is weaker $(r=0.4, \mathrm{p}<0.005)$. This is consistent with a previous in vitro study that showed that cultured human alveolar macrophages produced IL-8 in response to stimulation with LPS, but that this IL-8 was not sufficient to account for the total neutrophil chemotactic activity in the culture fluid. ${ }^{30}$

Previous studies have demonstrated a role for $\mathrm{TNF} \alpha$ in the response to inhaled endotoxin, with increases in blood, ${ }^{21}$ BAL fluid, ${ }^{11}$ and induced sputum. ${ }^{12}$ The reason for the lack of change in $\mathrm{TNF} \alpha$ concentrations in the present study is unclear but may be due to differences in sputum processing; we used the whole sputum sample whereas Michel et al used the technique of sputum plug selection. ${ }^{12}$ The concentrations of $\mathrm{TNF} \alpha$ measured were very low and in most samples, in normal subjects particularly, concentrations were below the limit of detection of the assay. This may be less of a problem using the technique of sputum plug selection as this decreases the dilutional effect of any salivary contamination of the sample.

Previous work has demonstrated that GMCSF is a primary endogenous regulator of neutrophil recruitment. It is known to stimulate IL-8 production by polymorphonuclear 
cells, ${ }^{31}$ it increases release of TNF $\alpha$ from cells of the monocyte macrophage line, ${ }^{32}$ and subcutaneous injections of human recombinant GM-CSF leads to increases in alveolar neutrophils with related increases in BAL fluid IL-8 concentrations. ${ }^{33}$ Endotoxin has been shown to be a potent stimulus for production and release of GM-CSF in vitro ${ }^{34}$; in view of this we hypothesised that GM-CSF may be released in the lung following inhalation of lipopolysaccharide and may play a role in neutrophil recruitment. However, we were unable to demonstrate an increase in GM-CSF concentrations within the lung in the present study. It remains to be determined whether changes in peripheral blood occur following inhalation of LPS. Our results are in agreement with a previous study in which dogs were treated with intravenous endotoxin ${ }^{35}$ and, although there were increases in plasma concentrations of granulocyte colony stimulating factor (G-CSF), there was no increase in the plasma concentrations of GM-CSF. As far as we are aware, there are no previous studies that have addressed the issue of GM-CSF concentrations within the lung following administration of LPS.

In conclusion, we have demonstrated an increase in total neutrophils at 24 hours in normal subjects, and a rapid increase in percentage of neutrophils in induced sputum at six hours following LPS inhalation in asthmatic subjects, which begins to resolve by 24 hours. Further evidence for an inflammatory effect of inhaled LPS is provided by the increased concentrations of IL- 8 seen in both normal and asthmatic subjects. Overall, there is no clear evidence that either atopy or asthma predisposes to an increase in the inflammatory effects of LPS at the dose used.

This study was performed with funding from Astra Draco AB.

1 Rosenthal S, Tager IB. Prevalence of Gram-negative rods in the normal pharyngeal flora. Ann Intern Med 1975;83:3557 .

2 Rylander R, Haglind P. Airborne endotoxins and humidifier disease. Clin Allergy 1984;14:109-12.

3 Flaherty DK, Deck FH, Cooper J, et al. Bacterial endotoxin isolated from a water spray humidification system as a putative agent of occupation-related lung disease. Infect Immunol 1984;43:206-12.

4 Rylander R. Bacteria as etiological agents in byssinosis and other lung disease. Eur $\mathcal{F}$ Respir Dis 1982;123(suppl):34 46.

5 Donham K, Haglind P, Peterson Y, et al. Environmental and health studies of farm workers in Swedish swine confinement buildings. British fournal of Industrial Medicine 1989, 46:31-7.

6 Thelin A, Teglin O, Rylander R. Lung reactions during poultry handling related to dust and bacterial endotoxin levels. Eur 7 Respir Dis 1984;65:266-71.

7 Cavagna G, Foa V, Vigliani EC. Effects in man and rabbits of inhalation of cotton dust or extracts and purified endotoxins. British fournal of Industrial Medicine 1969;26:31421 .

8 Rylander R, Bake B, Fischer JJ, et al. Pulmonary function and symptoms after inhalation of endotoxin. Am Rev Respir
and Dis 1989;140:981-6.

9 Michel O, Duchateau J, Sergysels R. Effect of inhaled endotoxin on bronchial reactivity in asthmatic and normal subjects. F Appl Physiol 1989;66:1059-64.
10 Sandstrom T, Bjermer L, Rylander R. Lipopolysaccharide (LPS) inhalation in healthy subjects increases neutrophils, ymphocytes and fibronectin levels in bronchoalveolar lavage fluid. Eur Respir F 1992;5:992-6.

11 Wesselius LJ, Nelson ME, Bailey K, et al. Rapid lung cytokine accumulation and neutrophil recruitment after lipopolysaccharide inhalation by cigarette smokers and nonsmokers. f Lab Clin Med 1997;129:106-14.

12 Michel O, Nagy A, Schroeven M, et al. Dose-response relationship to inhaled endotoxin in normal subjects. Am $\mathcal{7}$ Respir Crit Care Med 1997;156:1157-64.

13 Jagielo PJ, Thorne PS, Watt JL, et al. Grain dust and endotoxin inhalation challenges produce similar inflammatory responses in normal subjects. Chest 1996;110:263-70.

14 American Thoracic Society. Standards for the diagnosis and care of patients with chronic obstructive pulmonary disease (COPD) and asthma. Am Rev Respir Dis 1987;136:225-44.
Chai H, Farr RS, Froelich LA, et al. Standardization of bronchial challenge procedures. F Allergy Clin Immunol 1975;56:323-7.

16 Keatings VM, Collins PD, Scott DM, et al. Differences in interleukin-8 and tumor necrosis factor-alpha in induced sputum from patients with chronic obstructive pulmonary disease or asthma. Am f Respir Crit Care Med 1996;153: $530-4$.

17 Rylander R, Haglind P, Butcher BT. Reactions during work shift among cotton mill workers. Chest 1983;84:403-7.

18 Rylander R, Peterson Y. Organic dusts and lung disease. American fournal of Industrial Medicine 1990;17:1-149.

19 Jamison JP, Lowry RC. Bronchial challenge of normal subjects with the endotoxin of Enterobacter agglomerans isolated from cotton dust. British fournal of Industrial Medicine 1986;43:327-31.

20 Herbert A, Carvalheiro M, Rubenowitz E, et al. Reduction of alveolar-capillary diffusion after inhalation of endotoxin in normal subjects. Chest 1992;102:1095-8.

21 Michel O, Ginanni R, Le BB, et al. Inflammatory response to acute inhalation of endotoxin in asthmatic patients. $\mathrm{Am}$ Rev Respir Dis 1992;146:352-7.

22 Michel O, Ginanni R, Sergysels R. Relation between the bronchial obstructive response to inhaled lipopolysacchabronchial obstructive response to inhaled lipopolysaccha-
ride and bronchial responsiveness to histamine. Thorax ride and bronchial

23 Boulet LP, Turcotte H, Tennina S. Comparative efficacy of salbutamol, ipratropium and cromoglycate in the prevention of bronchospasm induced by exercise and hyperosmolar challenges. F Allergy Clin Immunol 1989;83:882-7.

24 Michel O, Duchateau J, Plat G, et al. Blood inflammatory response to inhaled endotoxin in normal subjects. Clin Exp Allergy 1995;25:73-9.

25 Nightingale JA, Rogers DF, Barnes PJ. The effect of repeated sputum induction on cell counts in normal volunreers. Thorax 1998;53:87-90.

26 Rylander R, Marchat B. Modulation of acute endotoxin pulmonary inflammation by a corticosteroid. f Clin Lab Immunol 1988;27:83-6.

27 Kang YH, Lee CH, Brummel SE, et al. Effects of endotoxin on expression of VLA integrins by human bronchoalveolar lavage macrophages. F Leuk Biol 1996;57:624-34.

28 Hirano S. Interaction of rat alveolar macrophages with pulmonary epithelial cells following exposure to lipopolysaccharide. Arch Toxicol 1996;70:230-6.

29 Bingisser R, Stey C, Weller M, et al. Apoptosis in human alveolar macrophages is induced by endotoxin and is modulated by cytokines. Am F Respir Cell Mol Biol 1996;15: 64-70.

30 Sylvester I, Rankin JA, Yoshimura T, et al. Secretion of neutrophil attractant/activation protein by lipopolysaccharidestimulated lung macrophages determined by both enzymelinked immmunosorbant assay and N-terminal sequence analysis. Am Rev Respir Dis 1990;141:683-8.

31 McCain RW, Dessypris EN, Christman JW. Granulocytemacrophage colony-stimulating factor stimulates human polymorphonuclear leukocytes to produce interleukin-8 in vitro. Am $\mathcal{F}$ Respir Cell Mol Biol 1993; 8:28-34.

32 Sisson SD, Dinarello CA. Production of interleukin-1a, interleukin-1b and tumour necrosis factor by human mononuclear cells stimulated with granulocytemacrophage colony-stimulating factor. Blood 1988;72: 1368-74.

33 Gatti E, Scagliotti GV, Ferrari G, et al. Blood cell redistribution in the lung after administration of recombinant human granulocyte-macrophage colony-stimulating factor. Eur Respir F 1995;8:1566-71.

34 Rennick D, Yang G, Gemmell L, et al. Control of haemopoiesis by bone marrow stromal cell clone: lipopolysaccharideand interleukin-1-inducible production of colonyand interleukin-1-inducible production

35 Dale DC, Lau S, Nash R, et al. Effect of endotoxin on serum granulocyte and granulocyte-macrophage colonystimulating factor levels in dogs. F Infect Dis 1992;165:68994. 